\title{
ANÁLISE DA SEXTA META DO PLANO NACIONAL DA EDUCAÇ̃̃O À LUZ DE INDICADORES DE MONITORAMENTO E AVALIAÇÃO
}

\author{
ANÁLISIS DEL SEXTO OBJETIVO DEL PLAN NACIONAL DE EDUCACIÓN A LA \\ LUZ DE LOS INDICADORES DE SEGUIMIENTO Y EVALUACIÓN
}

\author{
ANALYSIS OF THE SIXTH GOAL OF THE NATIONAL EDUCATION PLAN IN THE \\ LIGHT OF MONITORING AND EVALUATION INDICATORS
}

\author{
Solange Reiguel VIEIRA ${ }^{1}$ \\ Ângelo Ricardo de SOUZA ${ }^{2}$ \\ Marília Andrade TORALES-CAMPOS ${ }^{3}$
}

RESUMO: O artigo apresenta uma análise da sexta meta do Plano Nacional de Educação PNE (2014-2024) referente à educação integral com ênfase no Programa Federal Mais Educação. Para a análise da proposta foram feitos levantamentos bibliográficos e documentais do contexto da demanda educacional envolvida, das diretrizes/proposta da meta e suas estratégias para a política educacional, disponibilizadas na página institucional do PNE, vinculada ao Ministério da Educação. Para a análise da eficácia da meta até o presente momento, foram consultados relatórios do Instituto Nacional de Estudos e Pesquisas Educacionais Anísio Teixeira, referentes ao Censo Escolar da Educação Básica e cotejados com os indicadores de monitoramento do Observatório do PNE. Os resultados dos indicadores da meta 6 revelam que para o cumprimento da meta em 2024 é preciso ficar atento às oscilações e retrocessos nas políticas públicas referentes à educação integral, de forma a promover uma educação de qualidade aos estudantes da educação básica.

PALAVRAS-CHAVE: Avaliação. Política educacional. Plano nacional de educação. Educação integral. Indicadores.

RESUMEN: El artículo presenta un análisis del sexto objetivo del Plan Nacional de Educación - PNE (2014-2024) con respecto a la educación integral en el Programa Federal Más Educación. Para el análisis de la propuesta, se realizaron estudios bibliográficas y documentales del contexto de la demanda educativa involucrada, de las pautas o propuesta de la meta y sus estrategias de política educativa disponibles en la página institucional del PNE, vinculadas al Ministerio de Educación. Para analizar la efectividad de la meta hasta el momento, se consultaron informes del Censo Escolar de Educación Básica que han sido publicados por el Instituto Nacional de Estudios. Sobre ellos se ha realizado una comparación

${ }^{1}$ Universidade Federal do Paraná (UFPR), Curitiba - PR - Brasil. Doutoranda do Programa de Pós-Graduação em Educação (PPGE). ORCID: http://orcid.org/0000-0001-6889-0511. E-mail: solgeografia@gmail.com

${ }^{2}$ Universidade Federal do Paraná (UFPR), Curitiba - PR - Brasil. Professor Associado no Programa de PósGraduação em Educação (PPGE). Doutorado em Educação (PUC/SP). ORCID: https://orcid.org/0000-0002-02463207.E-mail: angelo@ufpr.br

${ }^{3}$ Universidade Federal do Paraná (UFPR), Curitiba - PR - Brasil. Professora Associada no Programa de PósGraduação em Educação (PPGE). Doutorado em Ciências da Educação (USC) - Espanha. Bolsista de Produtividade em Pesquisa do CNPq - Nível 2. ORCID: https://orcid.org/0000-0002-4026-6239. E-mail: marilia.torales@ufpr.br

RPGE- Revista on line de Política e Gestão Educacional, Araraquara, v. 24, n. 3, p. 1368-1386, set./dez. 2020. e-ISSN:1519-9029 
con los indicadores de monitoreo del Observatorio PNE. Los resultados de los indicadores de la meta 6 revelan que, para alcanzar la meta en 2024, es necesario estar al tanto de las fluctuaciones y retrocesos en las politicas públicas con respecto a la educación integral hacia promover una educación de calidad para los estudiantes de educación básica.

PALABRAS CLAVE: Evaluación. Política educativa. Plan nacional de educación. Educación integral. Indicadores.

ABSTRACT: The article presents an analysis of the sixth goal of the National Education Plan - PNE (2014-2024) regarding integral education with an emphasis on the Mais Educação Federal Program. For the analysis of the proposal, bibliographical and documentary surveys were made of the context of the educational demand involved, of the guidelines/proposal of the goal and its strategies for educational policy, available on the institutional page of the PNE, linked to the Ministry of Education. To analyze the effectiveness of the goal to date, reports from the Anisio Teixeira National Institute of Educational Studies and Research were consulted, referring to the School Census of Basic Education and compared with the monitoring indicators of the PNE Observatory. The results of the goal 6 indicators show that, in order to meet the goal in 2024, it is necessary to be aware of the fluctuations and setbacks in public policies regarding integral education, in order to promote quality education to basic education students.

KEYWORDS: Evaluation. Educational policy. National education plan. Integral education. Indicators.

\section{Introdução}

As pesquisas no campo da educação no Brasil, em especial na área de políticas educacionais tem se utilizado de dados qualitativos e quantitativos, com estudos focalizados em diferentes temáticas (GATTI, 2001), mas orientados no sentido de analisar a realidade educacional e propor alternativas de ação. O intuito destes estudos tem se caracterizado pela tentativa de compreender a complexidade das questões e os desafios contemporâneos postos à escola e a toda a sociedade, decorrentes do processo de globalização, das transformações técnico-científicas e as mudanças socioambientais ambientais globais, dentre outras, que têm demandado a "definição da agenda política dos Estados" (CARVALHO, 2006, p. 11).

Nesse processo, parte-se do entendimento de política pública como um campo do conhecimento que busca colocar o governo em ação. Nas palavras de Dye (1984) é o que o governo faz ou deixa de fazer. Após formuladas, as políticas "desdobram-se em planos, programas, projetos, bases de dados ou sistema de informação e pesquisas. Quando postas em ação, são implementadas, ficando daí submetidas a sistemas de acompanhamento e avaliação" (SOUZA, 2006, p. 26). 
Especificamente no campo de políticas educacionais, a partir da Constituição Federal de 1988, a educação pública é assegurada como um direito social, dever do Estado e da família, visando o pleno desenvolvimento da pessoa, seu preparo para o exercício da cidadania e sua qualificação para o trabalho.

Desde a aprovação da Lei 9.394/96, a educação está inserida nas políticas públicas do Estado brasileiro baseada no princípio do direito universal à educação de qualidade para todos e da gestão democrática, sendo a educação básica obrigatória e gratuita.

Conforme as Diretrizes Curriculares Nacionais da Educação Básica, a educação pública de qualidade se constitui em um dos fundamentos do projeto de Nação em construção, sendo a formação escolar, um alicerce indispensável e condição primeira para o exercício pleno da cidadania e o acesso aos direitos sociais, econômicos, civis e políticos (BRASIL, 2013).

Assim, se ampliam as possibilidades de avaliar as ações, os produtos e seus impactos, que requerem uma análise da relação entre a ação pública e as demandas sociais. Também se revela a necessidade de compreender a agenda política, a política propriamente dita, a execução e os resultados do processo (SOUZA, 2006).

De acordo com Ball, Maguire e Braun (2016, p. 37) "as políticas são definidas contra e ao lado de compromissos, valores e formas de experiências existentes". É neste contexto que o Plano Nacional de Educação (PNE) se constitui em uma peça da política nacional, cujas metas são desafios do Estado e da sociedade.

A Lei $n^{\circ} 13.005 / 2014$ que aprova o PNE, possui vigência por dez anos, prevista para o período de 2014 a 2024, com vistas ao cumprimento do disposto no Art. 214 da Constituição Federal, com o objetivo de articular o sistema nacional de educação em regime de colaboração e definir diretrizes, objetivos, metas e estratégias de implementação para assegurar a manutenção e desenvolvimento do ensino em diversos níveis, etapas e modalidades por meio de ações integradas dos poderes públicos das diferentes esferas federativas, que conduzam a:
I - Erradicação do analfabetismo;
II - Universalização do atendimento escolar;
III - melhoria da qualidade do ensino;
IV - Formação para o trabalho;
V - Promoção humanística, científica e tecnológica do País;
VI - Estabelecimento de meta de aplicação de recursos públicos em educação como proporção do produto interno bruto (BRASIL, 1988).

Dentre as metas estabelecidas no PNE, a meta 6 se propõe oferecer educação em tempo integral em, no mínimo, 50\% (cinquenta por cento) das escolas públicas, de forma a atender, pelo menos, 25\% (vinte e cinco por cento) dos (as) alunos (as) da educação básica. 
De acordo com Carvalho (2006), há debates que buscam consensos em torno do conceito da educação integral: esta pode ser compreendida como uma escola de tempo integral; uma conquista de qualidade da educação; como proteção e desenvolvimento integral; na aposta que mais tempo de escola aumenta a aprendizagem; e como complemento socioeducativo à escola, pela inserção de projetos sociais, culturais e esportivos.

Neste contexto da educação integral, o Programa Mais Educação se constitui em uma estratégia do Governo Federal para a ampliação da jornada escolar, que vai ao encontro dos objetivos da meta considerada nesta análise, à luz dos indicadores de monitoramento do Observatório do PNE. De acordo com Jannuzzi (2017, p. 13) os indicadores sociais são utilizados para "apontar a eficácia ou a ineficácia das políticas públicas ou defender suas posições quanto às prioridades sociais".

\section{A agenda política}

A análise de política segundo Muller e Surel (2002) pode ser realizada por meio de uma abordagem sequencial constituída pelas seguintes etapas: 1) agenda; 2) produção; 3) decisão; 4) implementação; 5) avaliação; 6) conclusão do programa. Estas etapas não possuem uma linearidade no processo da política.

De acordo com Mainardes (2006), a abordagem do ciclo de políticas, formulada pelos pesquisadores ingleses Ball e Bowe (1992), se constitui em uma ferramenta teóricometodológica para fundamentar a análise das políticas educacionais. Nesta tessitura, também se poderia considerar os contextos de influência, o contexto da produção de texto, o contexto da prática, o contexto dos resultados e o contexto da estratégia política como elementos de uma dinâmica que ora se configura como pano de fundo para diferentes questões, ora como elemento principal de análise.

A agenda das políticas públicas pode ser definida como um conjunto de problemas e pautas que necessitam de atenção do governo para compor o debate e a construção das políticas públicas. Nessa abordagem, a demanda da educação integral emerge da análise das desigualdades sociais e de pobreza que assolam o país, que requer a pactuação de uma agenda pela qualidade da educação para a consolidação de políticas públicas efetivas de inclusão social e do direito à educação, num processo de inserção societária mais igualitária (BRASIL, 2009; CARVALHO, 2006; MOLL, 2012; MOLL; LECLERC, 2013; SOUZA; ESPÍRITO SANTO; BERNADO, 2015; PARENTE, 2018). 
Conforme Parente (2018), a educação integral poder ser vista como uma alternativa ao enfrentamento de um problema público, como a vulnerabilidade social, o trabalho infantil, entre outras questões sociais a serem enfrentadas por meio da ampliação da jornada escolar, visando a necessária melhoria da qualidade da educação básica. Essa problemática de ordem social ou educacional, justifica a formulação de políticas públicas na perspectiva da educação em tempo integral.

A educação integral começou a ocupar a pauta da agenda política do Brasil a partir do século XX, num projeto de educação democrática e unitária seguindo marcos significativos na educação brasileira: Anísio Teixeira com as Escolas Parque e Escolas-classe entre os anos de 1940 e 1960; Darcy Ribeiro com os Centros de Educação Públicas (CIEP's) entre os anos 1980 e 1990, que visavam o aumento da jornada escolar; e Paulo Freire, com perspectiva de atender os estudantes das camadas populares com condições sociais adversas e muitas vezes por meio da entrada tardia na escola. Dessa forma, a educação integral se embasa legalmente na Constituição Federal para o enfrentamento das desigualdades; na LDB/96 Art. 34 e 87 na perspectiva da ampliação gradativa da jornada escolar para o regime de tempo integral; no Plano Nacional da Educação para a década de 2001-2010 com a proposta da ampliação progressiva da jornada escolar para 7 (sete) horas diárias e a participação das comunidades na gestão escolar; no FUNDEB/2007 determinando financiamento específico para a educação básica em tempo integral; no Plano de Desenvolvimento da Educação-PDE/2007, por meio do Programa Mais Educação; e no novo PDE planejado para 2011-2020 (Projeto de Lei nº 8.035/2010), aprovado para a década de 2014-2024, especificamente na meta 6 em jornada diária ampliada, a qual incorpora a educação integral no escopo da política pública do país (MOLL, 2012; MOLL; LECLERC, 2013).

As Diretrizes Curriculares Nacionais da Educação Básica determinam que para se estabelecer uma educação com um padrão mínimo de qualidade em tempo integral, é necessário:

investimento com valor calculado a partir das despesas essenciais ao desenvolvimento dos processos e procedimentos formativos, que levem, gradualmente, a uma educação integral, dotada de qualidade social: creches e escolas possuindo condições de infraestrutura e de adequados equipamentos e de acessibilidade; professores qualificados com remuneração adequada e compatível com a de outros profissionais com igual nível de formação, em regime de trabalho de 40 horas em tempo integral em uma mesma escola; definição de uma relação adequada entre o número de estudantes por turma e por professor, que assegure aprendizagens relevantes; pessoal de apoio técnico e administrativo que garanta o bom funcionamento da escola (BRASIL, 2013, p. 23). 
Nesse interim de educação em tempo integral, o Programa Mais Educação foi instituído pela Portaria Normativa Interministerial $n^{\circ} 17 / 07$ e regulamentado pelo Decreto $\mathrm{n}^{\mathrm{o}} 7.083 / 2010$, com o objetivo de fomentar a educação integral de crianças, adolescentes e jovens, por meio de atividades socioeducativas no contraturno escolar, articuladas ao projeto de ensino desenvolvido pela escola. Em seu Art. $1^{\circ}$ busca:

instituir o Programa Mais Educação, com o objetivo de contribuir para a formação integral de crianças, adolescentes e jovens, por meio da articulação de ações, de projetos e de programas do Governo Federal e suas contribuições às propostas, visões e práticas curriculares das redes públicas de ensino e das escolas, alterando o ambiente escolar e ampliando a oferta de saberes, métodos, processos e conteúdos educativos. Parágrafo único. O programa será implementado por meio do apoio à realização, em escolas e outros espaços socioculturais, de ações socioeducativas no contraturno escolar, incluindo os campos da educação, artes, cultura, esporte, lazer, mobilizando-os para a melhoria do desempenho educacional, ao cultivo de relações entre professores, alunos e suas comunidades, à garantia da proteção social da assistência social e à formação para a cidadania, incluindo perspectivas temáticas dos direitos humanos, consciência ambiental, novas tecnologias, comunicação social, saúde e consciência corporal, segurança alimentar e nutricional, convivência e democracia, compartilhamento comunitário e dinâmicas de redes (BRASIL, 2007).

Para Moll e Leclerc (2013, p. 293-294), esse programa traz desafios à política pública:

1) vivenciar uma escola que tenha jornada com duração contínua igual ou superior a sete horas diária, durante todo o ano letivo, compreendendo o tempo total que um mesmo aluno nela permanece; 2) vivenciar currículos como percursos formativos ao estudante, constituído por suas experiências escolares e comunitárias como a ciência, a tecnologia, a cultura, o mundo do trabalho, a arte, o esporte, o lazer, as políticas públicas, a vivência do respeito ao meio ambiente, a diversidade étnica, territorial, de classe, de gênero e de orientação sexual; 3) afirmar uma escola com uma jornada única, para todos os alunos.

Parente (2018, p. 417) apresenta uma distinção entre política de Estado - com medidas de continuidade, fortalecidas por ações legais, planejadas a longo prazo - e política de governo - aquelas que não apresentam perspectivas de continuidade para além dos mandatos. Essa diferenciação é importante para entender os contextos dos “programas e ações de ampliação de jornada escolar, ora caracterizados como políticas de governo, ora como políticas de Estado". A exemplo, o Programa Mais Educação que "pode ser caracterizado como um programa de governo, por sua vulnerabilidade às questões orçamentárias, administrativas e políticas".

Além do programa em questão, é visível a existência de políticas de educação integral em tempo integral no país, as quais se modificam conforme os fatores conjunturais e estruturais da educação e da sociedade (PARENTE, 2018). 
Nesse contexto, a partir do ano de 2016, com a mudança de Governo Federal, o referido programa foi descontinuado. Dele se originou o Programa Novo Mais Educação, criado pela Portaria MEC $n^{\circ} 1.144 / 2016$ e regido pela Resolução FNDE $n^{\circ} 17 / 2017$. Trata-se de uma estratégia do Ministério da Educação que tem como objetivo melhorar a aprendizagem em língua portuguesa e matemática no ensino fundamental, por meio da ampliação da jornada escolar de crianças e adolescentes, otimizando o tempo de permanência dos estudantes na escola. Em 2018, o programa começou a ser implementado nas escolas públicas de ensino fundamental, por meio de articulação institucional e cooperação com as secretarias estaduais, distrital e municipais de educação, mediante apoio técnico e financeiro do Ministério da Educação. A implementação está vinculada ao acompanhamento pedagógico em língua portuguesa e matemática e do desenvolvimento de atividades nos campos de artes, cultura, esporte e lazer, impulsionando a melhoria do desempenho educacional mediante a complementação da carga horária em cinco ou quinze horas semanais no turno e contraturno escolar. O programa tem por finalidade contribuir para a:

I - Alfabetização, ampliação do letramento e melhoria do desempenho em língua portuguesa e matemática das crianças e dos adolescentes, por meio de acompanhamento pedagógico específico;

II - Redução do abandono, da reprovação, da distorção idade/ano, mediante a implementação de ações pedagógicas para melhoria do rendimento e desempenho escolar;

III - Melhoria dos resultados de aprendizagem do ensino fundamental, nos anos iniciais e finais $-3^{\circ}$ e o $9^{\circ}$ ano do ensino fundamental regular;

IV - Ampliação do período de permanência dos alunos na escola (BRASIL, 2016).

$\mathrm{Na}$ atualidade, a temática educação integral faz parte da agenda da política educacional no âmbito nacional com o desafio de atingir a meta 6 do PNE de oferecer educação em tempo integral nas escolas públicas da educação básica, que será analisada a seguir.

\section{Análise da eficácia da meta 6}

A avaliação política, de acordo com Figueiredo e Figueiredo (1986), consiste em atribuir valor às políticas e apresenta a necessidade de estabelecer critérios de avaliação e escolha de uma política específica, certamente um trabalho complexo e controverso. Esta antecede à avaliação de políticas, no estabelecimento de conexões lógicas entre objetivos e critérios de avaliação, e modelos de análise de uma política ou programa. 
No que se refere-se à eficácia, a avaliação de processos afere a eficácia da execução do programa, conforme as diretrizes e metas propostas, dentro dos limites toleráveis (FIGUEIREDO; FIGUEIREDO, 1986).

Especificamente no âmbito da educação integral em jornada diária ampliada, o PNE propõe a sexta meta com o propósito de oferecer educação em tempo integral em, no mínimo, $50 \%$ (cinquenta por cento) das escolas públicas, de forma a atender, pelo menos, $25 \%$ (vinte e cinco por cento) dos(as) alunos(as) da educação básica, composta por nove estratégias específicas: 6.1) ampliação do tempo; 6.2) construção de escolas; 6.3) recursos - infraestrutura e equipamento, material; 6.4) articulação no território; 6.5) parcerias com entidades privadas; 6.6) parceria Ong-escola; 6.7) diversidade local; 6.8) tempo integral para pessoas com necessidades; 6.9) tempo de permanência (OPNE, 2019). As estratégias estão detalhadas a seguir:

6.1) promover, com o apoio da União, a oferta de educação básica pública em tempo integral, por meio de atividades de acompanhamento pedagógico e multidisciplinares, inclusive culturais e esportivas, de forma que o tempo de permanência dos(as) alunos(as) na escola, ou sob sua responsabilidade, passe a ser igual ou superior a 7 (sete) horas diárias durante todo o ano letivo, com a ampliação progressiva da jornada de professores em uma única escola; 6.2) instituir, em regime de colaboração, programa de construção de escolas com padrão arquitetônico e de mobiliário adequado para atendimento em tempo integral, prioritariamente em comunidades pobres ou com crianças em situação de vulnerabilidade social;

6.3) institucionalizar e manter, em regime de colaboração, programa nacional de ampliação e reestruturação das escolas públicas, por meio da instalação de quadras poliesportivas, laboratórios, inclusive de informática, espaços para atividades culturais, bibliotecas, auditórios, cozinhas, refeitórios, banheiros e outros equipamentos, bem como da produção de material didático e da formação de recursos humanos para a educação em tempo integral;

6.4) fomentar a articulação da escola com os diferentes espaços educativos, culturais e esportivos e com equipamentos públicos, como centros comunitários, bibliotecas, praças, parques, museus, teatros, cinemas e planetários;

6.5) estimular a oferta de atividades voltadas à ampliação da jornada escolar de alunos(as) matriculados nas escolas da rede pública de educação básica por parte das entidades privadas de serviço social vinculadas ao sistema sindical, de forma concomitante e em articulação com a rede pública de ensino;

6.6) orientar a aplicação da gratuidade de que trata o Art. 13 da Lei $n^{\circ} 12.101$, de 27 de novembro de 2009, em atividades de ampliação da jornada escolar de alunos(as) das escolas da rede pública de educação básica, de forma concomitante e em articulação com a rede pública de ensino;

6.7) atender às escolas do campo e de comunidades indígenas e quilombolas na oferta de educação em tempo integral, com base em consulta prévia e informada, considerando-se as peculiaridades locais;

6.8) garantir a educação em tempo integral para pessoas com deficiência, transtornos globais do desenvolvimento e altas habilidades ou superdotação na faixa etária de 4 (quatro) a 17 (dezessete) anos, assegurando atendimento 
educacional especializado complementar e suplementar ofertado em salas de recursos multifuncionais da própria escola ou em instituições especializadas; 6.9) adotar medidas para otimizar o tempo de permanência dos alunos na escola, direcionando a expansão da jornada para o efetivo trabalho escolar, combinado com atividades recreativas, esportivas e culturais (BRASIL, 2014).

Em suma, a meta consiste em ampliar o tempo de permanência de crianças, adolescentes e jovens matriculados nas escolas públicas, com o desafio da ampliação de tempos, espaços, atividades educativas e oportunidades educacionais, visando a melhoria da qualidade da educação dos alunos da educação básica (BRASIL, 2015a).

Toma-se como principal referência de análise a linha de base dos indicadores construídos trabalho conjunto do Ministério da Educação e pelo Instituto Nacional de Estudos e Pesquisas Educacionais Anísio Teixeira (Inep) para o monitoramento do Plano Nacional de Educação 2014-2024 (PNE), selecionados como os indicadores mais adequados para o acompanhamento e avaliação das metas estabelecidas no Plano (BRASIL, 2015a).

Conforme Jannuzzi (2017, p. 150), os indicadores sociais são fundamentais para formulação e avaliação de políticas públicas. Na etapa da avaliação, devem-se empregar indicadores que "respondam pela eficácia (o programa cumpriu seus objetivos?), pela eficiência (os recursos foram bem empregados?) e pela efetividade social (quais os impactos efetivos gerados pelo programa nos beneficiários e na sociedade?)".

Nesta análise se considera os indicadores $6 \mathrm{~A}$ e $6 \mathrm{~B}$ da sexta meta da educação em tempo integral, de abrangência nacional, elaborados a partir dos dados do Censo Escolar da Educação Básica da série histórica 2009-2013 (BRASIL, 2015a), com o propósito de avaliar a eficácia no atingimento da meta/resultado de $50 \%$ das escolas públicas, de forma a atender, pelo menos, $25 \%$ dos alunos de toda a educação básica.

Conforme dados do Inep referente ao Censo Escolar 2012, das 192.676 escolas de educação básica que tinham matrículas escolares, 42.884 tinham tempo integral, com uma cobertura de $22 \%$ do total de escolas da educação básica, o que representa menos da metade da meta a ser atingida nos 10 anos de vigência do Plano (MOLL; LECLERC, 2013).

No Censo Escolar 2018 (BRASIL, 2018), foram registradas 48,5 milhões de matrículas nas 181,9 mil escolas de educação básica brasileiras, 1,3 milhão a menos em comparação com o ano de 2014, o que corresponde a uma redução de 2,6\% no total de matrículas. Com base nos dados apresentados na Tabela 1, pode-se observar um crescimento de 17,8\% nas matrículas em tempo integral do ensino médio, de 2017 para 2018. 
Tabela 1 - Percentual de matrículas em tempo integral

\begin{tabular}{c|c|c|c|c|c|c}
\hline \multirow{2}{*}{ Ano } & \multicolumn{6}{|c}{ ETAPA DE ENSINO E REDE } \\
\cline { 2 - 7 } & \multicolumn{3}{|c}{ Ensino Fundamental } & \multicolumn{3}{c}{ Ensino Médio } \\
\cline { 2 - 7 } & Total & Pública & Privada & Total & Pública & Privada \\
\hline 2014 & $15,7 \%$ & $18,2 \%$ & $2,4 \%$ & $5,4 \%$ & $5,7 \%$ & $3,3 \%$ \\
\hline 2015 & $16,7 \%$ & $19,4 \%$ & $2,5 \%$ & $5,9 \%$ & $6,3 \%$ & $3,5 \%$ \\
\hline 2016 & $9,1 \%$ & $10,5 \%$ & $2,0 \%$ & $6,4 \%$ & $6,7 \%$ & $3,8 \%$ \\
\hline 2017 & $13,9 \%$ & $16,3 \%$ & $2,1 \%$ & $7,9 \%$ & $8,4 \%$ & $3,9 \%$ \\
\hline 2018 & $9,4 \%$ & $10,9 \%$ & $2,2 \%$ & $9,5 \%$ & $10,3 \%$ & $4,0 \%$ \\
\hline
\end{tabular}

Fonte: Organizado pela autora com base nos dados do Censo Escolar - Inep 2018 (BRASIL, 2018)

Entretanto, na educação infantil e no ensino fundamental, existiu uma queda nas matrículas de estudantes que têm pelo menos sete horas diárias de atividades escolares, mesmo somando-se a duração da escolarização com as atividades complementares.

Ao trazer os dados mais detalhados por modalidade de ensino, temos as seguintes mensurações: na educação infantil, em 2018 o percentual dos alunos matriculados em creches de tempo integral foi de 56,6\%. Este dado representa uma redução de 2,1 \% em relação ao ano de 2014. Esta redução também é observada na pré-escola, cujo percentual de 11,5\% em 2017 caiu para $11,1 \%$ em 2018. Todavia, ao avaliar a série histórica, percebe-se uma certa estabilidade nos últimos anos. No ensino fundamental, 9,4\% das matrículas do ensino fundamental permaneceram sete horas diárias ou mais em atividades escolares em 2018. A proporção de matrículas de tempo integral é substancialmente menor na rede privada do que na rede pública, representando apenas $2,2 \%$ das matrículas. No ensino médio, 9,5\% dos estudantes matriculados permaneceram sete horas diárias ou mais em atividades escolares. No ano de 2017, esse percentual era de 7,9\%. A proporção de matrículas de tempo integral é maior na rede pública (10,3\%) do que na rede privada (4\%). Desde 2014, a proporção de matrículas da rede pública classificadas como de tempo integral aumentou 4,6 pontos percentuais. O percentual de alunos que passam pelo menos sete horas diárias na escola passou de 7,9\% em 2017, para 9,5\% em 2018, caracterizando-os como alunos de tempo integral.

Ao cotejar os dados do Inep com os Indicadores do OPNE, em relação ao primeiro objetivo da meta - oferecer em, no mínimo, 50\% das escolas públicas jornadas diárias de sete horas ou mais até 2024 -, com a estratégia específica 6.1 de ampliação do tempo, se apresenta o resultado parcial: no ano de 2014, 42\% das escolas públicas ofertavam a educação em tempo integral; em 2015 houve um expressivo aumento, alcançando 44,3\%; em 2016 foi registrado um decréscimo para 32,3\% de escolas; e uma elevação em 2017 para $40,1 \%$. No que se refere ao segundo objetivo - garantir que, no mínimo, 25\% dos alunos da educação básica sejam atendidos em jornadas diárias de sete horas ou mais até 
2024 - o resultado parcial em 2017 foi de que 15,3\% das matrículas eram em educação em tempo integral.

A seguir serão apresentados os dois principais indicadores construídos para aferição do cumprimento da meta 6 e os resultados do monitoramento da meta no contexto nacional, disponibilizados com atualização na página institucional do Observatório do PNE. Estes Indicadores de Monitoramento do PNE, foram elaborados pelo programa Todos Pela Educação a partir dos dados do Censo Escolar, com objetivo de colaborar no cumprimento do seu papel como agenda norteadora das políticas educacionais no País. Nesta meta duas questões principais surgiram: "Qual o percentual de alunos da educação básica que estão matriculados em educação de tempo integral? Qual o percentual de escolas públicas da educação básica que ofertam ao menos uma matrícula em tempo integral?" (BRASIL, 2015a, p. 99). A partir destas questões norteadoras foram definidos os dois indicadores da meta com as seguintes funções iniciais: "O Indicador $6 \mathrm{~A}$ afere o percentual de matrículas em tempo integral, ou seja, aquelas matrículas com jornada diária total de ao menos sete horas. O Indicador 6B revela o valor percentual de escolas que oferecem ao menos uma matrícula em tempo integral” (BRASIL, 2015a, p. 109).

A seguir uma apresentação de cada Indicador com uma breve descrição de como foi construído e também a fórmula de cálculo (BRASIL, 2015a; 2015b), seguido pelos resultados do OPNE (BRASIL, 2019b).

O Indicador 6A - Porcentagem de escolas públicas da educação básica com matrículas em tempo integral - mostra a quantidade de escolas da educação básica que possuem alunos matriculados em período integral, ou seja, em jornada média diária de sete horas. Possui três níveis de proporção, mais de 50\%, mais de 75\% e 100\% das matrículas, que representa a porcentagem de alunos dentro dessas escolas que estão em tempo integral. Este Indicador possibilita o acesso por instituições que possuem, pelo menos, um dos seus alunos nessa modalidade de ensino, bem como, as informações por redes de ensino.

Segundo dados da ficha técnica da meta 6, para o cálculo do Indicador 6A, foram consideradas todas as matrículas do ensino público regular na educação infantil, no ensino fundamental e no ensino médio, incluindo o ensino médio integrado e concomitante à educação profissional. No cálculo do tempo total diário de atividades dessas matrículas, foi contabilizado o tempo de escolarização nas turmas do ensino regular mais a duração da atividade complementar do aluno e, quando fosse o caso, do tempo de atendimento 
educacional especializado. Sendo considerado matrícula em tempo integral o resultado igual ou superior a 7 horas diárias por aluno (BRASIL, 2015b). A fórmula do cálculo é:

$$
\begin{aligned}
& \begin{array}{l}
\text { número de escolas públicas que alunos permanecem no mínimo } 7 \text { horas } \\
\text { diárias em atividades escolares }
\end{array} \\
& \text { número total de matrículas }
\end{aligned} 100
$$

Segundo dados do OPNE (2019), entre 2011 a 2015, foi observado um crescimento continuado da porcentagem das escolas públicas com matrículas em tempo integral. Em 2015 houve um aumento considerável de 14,9 pontos percentuais, atingindo a marca de 41,7\% de escolas. Em 2016, esse Indicador apresentou uma queda de 9,5 pontos percentuais, voltando a crescer em 2017 , quando contou com $38,4 \%$ das escolas públicas da educação básica com alunos matriculados nessa modalidade de ensino.

Ao comparar as escolas de tempo integral no âmbito da educação básica por dependência administrativa, nota-se que a rede pública apresentava a maior porcentagem de escolas com 40,1\%, enquanto a privada contava com 32,2\% em 2017. Essa realidade foi controversa no ano 2011, sendo notada um índice maior da rede privada $(29,8 \%) \mathrm{em}$ comparação com a pública $(26,1 \%)$.

$\mathrm{Na}$ análise das escolas da rede pública por etapa, verifica-se que todas sofreram quedas em 2016, sendo o ensino fundamental a etapa com maior porcentagem de escolas em tempo integral. A educação infantil teve um percentual de $24,7 \%$ de escolas. O ensino fundamental teve $34 \%$ de escolas. Enquanto o ensino médio alcançou 17,4\% de escolas que oferecem ensino em tempo integral.

Com relação aos níveis de proporção $(50 \%, 75 \%$ e 100\%) dos alunos matriculados em tempo integral temos os seguintes dados: no ano de 2017, 27.109 escolas da educação básica $(18,8 \%)$ possuíam mais de $50 \%$ de seus alunos na educação em tempo integral. Esse dado mostra a maior proporção de crescimento desde 2011 com 8,4 pontos percentuais. No mesmo período, houve um total de 25.140 escolas $(13,7 \%)$ com mais de $75 \%$ dos estudantes em tempo integral. Sendo que 19.325 escolas brasileiras $(10,5 \%)$ têm todos os alunos nessa modalidade de ensino.

Ao analisar esses dados a partir das redes de ensino, as escolas com mais de 50\% de seus alunos matriculados em jornadas diárias de sete horas, em 2017 correspondiam a $21,8 \%$ das instituições privadas e 18,8\% públicas. Das escolas com mais de 75\%, 19,5\% são privadas e 12,1\% públicas. Enquanto possuíam todos os estudantes em tempo integral $18,1 \%$ são da rede privada e $8,4 \%$ da pública. 


\section{O Indicador 6B - Porcentagem de matrículas na rede pública em tempo integral}

na educação básica - mostra a quantidade de escolas da educação básica de cada localidade pela proporção de suas matrículas feitas em período integral, tendo pelo menos, uma jornada média diária de sete horas.

Conforme dados da ficha técnica da meta 6 , o indicador $6 \mathrm{~B}$ representa a proporção de escolas públicas com pelo menos um aluno que permanece, no mínimo, 7 horas em atividades escolares diárias, em relação ao total de escolas públicas. O Indicador foi construído da seguinte forma:

com base nas escolas que possuem matrículas em tempo integral. Para o cálculo do tempo total diário de atividades dessas matrículas, contabilizou-se o tempo de escolarização acrescido da duração da atividade complementar do aluno e, quando fosse o caso, do tempo de atendimento educacional especializado. Quando este somatório é igual ou superior a 7 horas diárias por aluno, considera-se que a matrícula é em tempo integral. Foram consideradas todas as matrículas do ensino regular na educação infantil, no ensino fundamental e no ensino médio. A exclusão da modalidade educação de jovens e adultos é baseada na concepção de que a educação em tempo integral não tem especificidade para a natureza pedagógica da EJA - que atende particularmente os jovens e adultos que dividem a jornada diária entre os estudos no período noturno e a inserção produtiva durante o dia. As escolas exclusivas para $o$ atendimento de pessoas com deficiência também não são objeto do presente estudo, visto que o projeto de escolas públicas em tempo integral é contemplado apenas nas escolas regulares (BRASIL, 2015b).

A apuração do indicador se considera o número de alunos matriculados em jornada média diária de sete horas. A fórmula do cálculo do Indicador 6B é:

número de escolas públicas com pelo menos 1 aluno que permanece no mínimo 7 horas em atividades escolares número total de escolas $-x 100$

Os dados deste Indicador mostram um notável crescimento de 2011 a 2015 na porcentagem de alunos matriculados na rede pública em tempo integral, com 9,2 pontos percentuais, atingindo $16,7 \%$ em 2015. Porém, no ano de 2016 houve uma queda de 5,2 pontos percentuais, alcançando 11,5\%. Já em 2017, as matrículas em tempo integral voltaram a subir, atingindo $15,3 \%$, totalizando aproximadamente 6 milhões de alunos matriculados em tempo integral nas escolas públicas em 2017.

Este Indicador disponibiliza também o percentual de matrículas da rede pública por etapa de ensino, que dá visibilidade à oferta da educação integral. Conforme o OPNE, a educação infantil da rede pública já cumpriu a meta em 2011 , quando contava com $25,3 \%$ das 
matrículas em tempo integral; em 2016 esse índice aumentou e chegou a 28,2\%. Essa observação também se dá nas matrículas da educação básica, entre os anos de 2015 e 2016, quando a taxa apresentou uma queda de 0,5 ponto percentual, voltando a crescer em 2017 para 28,8\%. No ensino fundamental apresentou um crescimento entre 2011 e 2015, subindo 13 pontos percentuais e alcançando 19,4\% de matrículas em 2015. No intervalo de 2015-2016, o índice apresentou a sua primeira queda desde o início da série histórica, e a maior já reportada entre os dados citados com 8,9 pontos percentuais. No ano de 2017, esse valor subiu para $16,3 \%$. O ensino médio não acompanhou o ritmo das outras etapas e manteve uma porcentagem inferior às demais, com um total de 8,4\% de matrículas em escolas de tempo integral em 2017. Ainda assim, foi a única etapa que apresentou crescimento em todos os anos desde 2011 chegando a 5,6 pontos percentuais.

Tendo em vista o alcance da meta 6 e suas estratégias para a eficácia e avanço na qualidade da educação básica no Brasil espera-se que:

Tais estratégias prescrevem a adoção de políticas públicas que subsidiem a ampliação dos recursos necessários ao atendimento nas escolas públicas em tempo integral, a partir da melhoria do aporte de insumos educacionais e da infraestrutura das escolas, com adequados padrões arquitetônicos e de mobiliário, da ampliação da permanência dos professores em uma única escola, das parcerias para o uso do espaço público para atividades educativas, da garantia de educação integral assistida pelo atendimento educacional especializado para pessoas com deficiência, transtornos globais do desenvolvimento e altas habilidades ou superdotação, dentre outras indicações de valorização do direito à educação. Se executadas na integralidade, essas estratégias têm grande potencial de indução da quarta diretriz do PNE: a melhoria da qualidade da educação básica (BRASIL, 2015a).

Nesse sentido, além de dobrar a proporção de escolas com educação integral para chegar à meta proposta no PNE, de universalizar no âmbito de cada escola o direito ao tempo integral, também é preciso garantir uma concepção de currículo que contemple a formação dos professores, a infraestrutura, a gestão, o financiamento e o protagonismo dos estudantes (MOLL; LECLERC, 2013; SOUZA; ESPÍRITO SANTO; BERNADO, 2015).

Jannuzzi (2017) enfatiza que o uso de indicadores requer compreensão de seus conceitos e limites. Nesse sentido, os indicadores 6A e 6B apresentados pelo OPNE, são modelos que traduzem, em certa medida, a realidade da educação nacional ao considerar o total de escolas e número de estudantes da educação básica na modalidade de tempo integral, mas reconhecem a limitação de se utilizar apenas o tempo como parâmetro para monitorar a meta. Não são captados pelos indicadores aspectos referentes às atividades pedagógicas desenvolvidas nesta 
carga horária de tempo ampliado, que atribuem valor à qualidade do ensino ofertado aos alunos durante a jornada escolar.

Se evidencia um desafio da educação integral de propiciar oportunidades de aprendizagem e acesso à cultura, à arte, ao esporte, à ciência e à tecnologia, por meio de atividades planejadas e alinhadas ao projeto político-pedagógico da escola, e não somente língua portuguesa e matemática, pois entende-se que as temáticas diversificadas também contribuem para a aprendizagem, e consequentemente para a elevação do Índice da Educação Básica - Ideb.

Na mesma linha de pensamento, para a análise da eficácia da sexta meta do PNE, cuja proposta é a ampliação da jornada diária de forma gradativa nas escolas públicas brasileiras, seria necessário um aprofundamento nas relações pedagógicas existentes entre o espaço físico da escola, as atividades pedagógicas e o tempo escolar ampliado. Também se enuncia uma relação entre as 20 metas propostas no PNE, principalmente no que se refere à garantia do direito à educação e a redução das desigualdades, que depende do alcance de outras metas para executá-las, principalmente as dedicadas à gestão democrática, na formação e valorização docente, universalização do ensino e financiamento da educação pública, incluindo as metas 2 , 3, 4, 7, 15, 17, 19 e 20 (SOUZA; ESPÍRITO SANTO; BERNADO, 2015).

Enfim, a utilização de indicadores sociais contribui para, "ao se retratar o presente e cotejá-lo com o passado, construir os caminhos para se alcançar o futuro almejado" (JANNUZZI, 2017, p. 186). Assim, de acordo com os resultados dos Indicadores de Monitoramento do OPNE, para o cumprimento da meta em 2024 é preciso ficar atento às oscilações e retrocessos nas políticas públicas.

\section{Considerações finais}

O processo de avaliação de política é certamente complexo, desafiador e ao mesmo tempo extremamente relevante, especialmente para o fortalecimento do campo das políticas educacionais.

$\mathrm{Na}$ atualidade, a temática da educação integral está contemplada na agenda da política educacional, porém não há garantias da permanência ou retirada dela, nem que sua manutenção repercutirá na formulação de políticas efetivas na área, pois depende de diversos fatores conjunturais (PARENTE, 2018, p. 422). Há uma questão latente acerca da sexta meta para 2024 apresentada por Souza, Espírito Santo e Bernado (2015, p. 157) que merece reflexão: 
Será que as conjunturas dos atuais sistemas/redes de ensino brasileiros, que parecem não dar conta de tantos estudantes do nível fundamental, terão composição estrutural para cumprir a meta do PNE, incorporando um considerável acréscimo na carga horária diária na escola para $25 \%$ da população estudantil?

Ademais, deve-se considerar os diversos contextos desta política pública posta em pauta, a qual está sendo implementada pelos diversos sujeitos do país em diferentes compreensões e condições que precisariam ser consideradas na análise numa perspectiva da micropolítica.

Com base no esforço realizado neste trabalho de análise da sexta meta do Plano Nacional de Educação e nos resultados dos Indicadores do OPNE, a educação integral se constitui em uma alternativa para os problemas da educação brasileira e a melhoria da qualidade do ensino ofertados aos estudantes. Há uma tendência importante à ampliação da jornada escolar no Brasil na perspectiva da educação integral, sendo alcançada em anos anteriores, mas existe um longo caminho a ser percorrido para que a meta seja cumprida até 2024, num esforço coletivo entre sociedade e Governo (CARVALHO, 2006; MOLL; LECLERC, 2013; PARENTE, 2018).

Outra observação relevante é a notável relação existente entre esta meta com as demais estratégias do PNE, o que necessitaria de análise conjunta para dar conta da compreensão da complexidade da educação integral. Poder-se-ia por exemplo, fazer uma inter-relação entre os Indicadores do Observatório do PNE, de grande relevância para os futuros estudos da temática em pauta, bem como o campo das políticas educacionais.

\section{REFERÊNCIAS}

BALL, S. J.; BOWE, R. Subject departments and the "implementation" of National Curriculum policy: an overview of the issues. Journal of Curriculum Studies, Londres, v. 24, n. 2, p. 97-115, abr. 1992. ISSN: ISSN-0022-0272.

BALL, S. J.; MAGUIRE, M.; BRAUN, A. Como as escolas fazem as políticas: atuação em escolas secundárias. Trad. Janete Bridon. Ponta Grossa: Editora UEPG, 2016.

BRASIL. Constituição [1988]. Constituição da República Federal do Brasil. Brasília, DF: Senado Federal, 1988.

BRASIL. Lei n. 9.394, de 20 de dezembro de 1996. Estabelece as diretrizes e bases da educação nacional. Diário Oficial da União: Seção 1, Brasília, DF, p. 27833, 23 dez. 1996. PL 1258/1988 
BRASIL. Lei n. 10.172, de 9 de janeiro de 2001. Aprova o Plano Nacional de Educação e dá outras providências. Diário Oficial da União: Seção 1, Brasília, DF, p. 1, 10 jan. 2001. PL $4155 / 1998$

BRASIL. Portaria Normativa Interministerial n. 17, de 24 de abril de 2007. Institui o Programa Mais Educação que visa fomentar a educação integral de crianças, adolescentes e jovens, por meio do apoio a atividades socioeducativas no contraturno escolar. Diário Oficial da União: Seção 1, Brasília, DF, n. 80, p. 5-6, 26 abr. 2007 a.

BRASIL. Decreto n. 6.253, de 13 de novembro de 2007. Dispõe sobre o Fundo de Manutenção e Desenvolvimento da Educação Básica e de Valorização dos Profissionais da Educação - FUNDEB, regulamenta a Lei no 11.494, de 20 de junho de 2007, e dá outras providências. Diário Oficial da União: Seção 1, Brasília, DF, p. 18, 14 nov. 2007b.

BRASIL. Ministério da Educação. Secretaria de Educação Continuada e Diversidade (Secadi). Educação integral: texto referência para o debate nacional. Brasília: MEC/Secadi, 2009. (Série Mais Educação)

BRASIL. Decreto n. 7.083, de 27 de janeiro de 2010. Dispõe sobre o Programa Mais Educação. Diário Oficial da União: Seção 1, Brasília, DF, p. 2, 27 jan. 2010a.

BRASIL. Câmara dos Deputados. Projeto de Lei n. 8.035, de 20 de dezembro de 2010. Aprova o Plano Nacional de Educação para o decênio 2011-2020 e dá outras providências. Brasília, DF: Câmara dos Deputados, 2010b. Disponível em: https://www.camara.leg.br/proposicoesWeb/prop_mostrarintegra?codteor=831421\&filename $=\mathrm{PL}+8035 / 2010$. Acesso em: 10 set. 2020.

BRASIL. Diretrizes Curriculares Nacionais Gerais da Educação Básica. Ministério da Educação. Secretaria de Educação Básica. Secretaria de Educação Continuada, Alfabetização, Diversidade e Inclusão. Secretaria de Educação Profissional e Tecnológica. Conselho Nacional da Educação. Câmara Nacional de Educação Básica. Diretoria de Currículos e Educação Integral. Brasília: MEC, SEB, DICEI, 2013.

BRASIL. Câmara dos Deputados. Lei n. 13.005, de 25 de junho de 2014. Aprova o Plano Nacional de Educação para o decênio 2014-2024 e dá outras providências. Diário Oficial da União: Seção 1, Brasília, DF: Câmara dos Deputados, p. 1, 26 jun. 2014. PL 8035/2010

BRASIL. Instituto Nacional de Estudos e Pesquisas Educacionais Anísio Teixeira. Plano Nacional de Educação PNE 2014-2024: Linha de Base. Brasília, DF: Inep, 2015a.

BRASIL. Instituto Nacional de Estudos e Pesquisas Educacionais Anísio Teixeira. Plano Nacional de Educação PNE 2014-2024: Ficha Técnica Meta 6. Brasília, DF: Inep, 2015 b.

BRASIL. Ministério da Educação. Portaria n. 1.144, de 10 de outubro de 2016. Institui o Programa Novo Mais Educação, que visa melhorar a aprendizagem em língua portuguesa e matemática no ensino fundamental. Diário Oficial da União: Seção 1, Brasília, DF, n. 186, p. 23, 10 out. 2016.

BRASIL. Ministério da Educação. Instituto Nacional de Estudos e Pesquisas Educacionais Anísio Teixeira (INEP). Censo da Escolar da Educação Básica. Brasília, DF: Inep, 2018. 
BRASIL. Portal Inep. 2019a. Disponível em: http://portal.inep.gov.br/artigo//asset_publisher/B4AQV9zFY7Bv/content/dados-do-censo-escolar-matriculas-em-tempointegral-cresceram-17-8-no-ensino-medio-de-2017-para-2018/21206. Acesso em: 4 ago. 2019.

BRASIL. Observatório do PNE. 2019b. Disponível em:

http://www.observatoriodopne.org.br/indicadores/metas/6-educacao-integral/indicadores>. Acesso em: 4 ago. 2019.

CARVALHO, M. C. B. O lugar da educação integral na política social. Cadernos CENPEC, São Paulo, v. 1, n. 2, p. 7-11, 2006. ISSN 2237-9983.

DYE, T. R. Understanding public policy. Englewood Cliffs: N.J.: Prentice Hall, 1984.

FIGUEIREDO, M. F.; FIGUEIREDO, A. M. C. Avaliação política e avaliação de políticas: um quadro de referência teórica. Análise \& Conjuntura, Belo Horizonte, v. 1, n. 3, set./dez. 1986.

GATTI, B. A. Implicações e Perspectivas da Pesquisa Educacional no Brasil Contemporâneo. Cadernos de Pesquisa, São Paulo, n. 113, p. 65-81, jul. 2001. ISSN 1980-5314.

JANNUZZI, P. M. Indicadores Sociais no Brasil: conceitos, fontes de dados e aplicações. 6. ed. Campinas-SP: Alínea, 2017.

MAINARDES, J. Abordagem do ciclo de políticas: uma contribuição para a análise de políticas educacionais. Educação \& Sociedade, Campinas, v. 27, n. 94, p. 47-69, jan./abr. 2006. ISSN 1678-4626.

MOLL, J. A agenda da educação integral: compromissos para consolidação da política pública. In: MOLL, J. (Org.). Caminhos da educação integral no Brasil: direito a outros tempos educativos. Porto Alegre: Artmed, 2012. p. 129-146.

MOLL, J.; LECLERC, G. F. E. Diversidade e tempo integral: a garantia dos direitos sociais. Revista Retratos da Escola, Brasília, v. 7, n. 13, p. 291-304, jul./dez. 2013. ISSN: 1982$131 \mathrm{X}$

MULLER, P.; SUREL, Y. A análise das políticas públicas. Pelotas: Educat, 2002.

PARENTE, C. M. D. Políticas de educação integral em tempo integral à luz da análise do ciclo de política pública. Educação \& Realidade, Porto Alegre, v. 43, n. 2, p. 415-434, abr./jun. 2018. ISSN 2175-6236.

SOUZA, Â. R. A política educacional e seus objetos de estudo. Revista de Estudios Teóricos y Epistemológicos en Política Educativa, Buenos Aires, v. 1, n. 1, p. 75-89, jan./jun. 2016. ISSN 2409-3696.

SOUZA, G. J. A.; ESPÍRITO SANTO, N. C.; BERNADO, E. S. A sexta meta do PNE 20142024: um diálogo possível em busca de uma educação integral e(m) tempo integral. EccoS Revista Científica, São Paulo, n. 37, p. 143-160, maio/ago. 2015. ISSN 1983-9278. 
SOUZA, C. Políticas Públicas: uma revisão da literatura. Sociologias, Porto Alegre, ano 8, n. 16, p. 20-45, jul./dez. 2006. ISSN 1807-0337.

\section{Como referenciar este artigo}

VIEIRA, S. R.; SOUZA, Â. R.; TORALES-CAMPOS, M. A. Análise da sexta meta do Plano Nacional da Educação à luz de indicadores de monitoramento e avaliação. Revista on line de Política e Gestão Educacional, Araraquara, v. 24, n. 3, p. 1368-1386, set./dez. 2020. eISSN:1519-9029. DOI: https://doi.org/10.22633/rpge.v24i3.13763

Submetido em: 08/06/2020

Aprovado em: 10/08/2020

Publicado em: 01/09/2020 